\title{
Can Global Economic Policy Uncertainty Drive the Interdependence of Agricultural Commodity Prices? Evidence from Partial Wavelet Coherence Analysis
}

\author{
Siaw Frimpong $\mathbb{D}^{\mathbb{D}},{ }^{1}$ Emmanuel N. Gyamfi $\mathbb{D}^{\mathbb{D}},{ }^{2}$ Zangina Ishaq $\mathbb{D}^{\mathbb{D}},{ }^{1}$ Samuel Kwaku Agyei $\mathbb{D}^{\mathbb{D}},{ }^{1}$ \\ Daniel Agyapong $\left(\mathbb{D},{ }^{1}\right.$ and Anokye M. Adam $\left(\mathbb{D}^{1}\right.$ \\ ${ }^{1}$ Department of Finance, School of Business, University of Cape Coast, Cape Coast, Ghana \\ ${ }^{2}$ GIMPA Business School, Accra, Ghana \\ Correspondence should be addressed to Anokye M. Adam; aadam@ucc.edu.gh
}

Received 6 August 2020; Revised 10 May 2021; Accepted 26 May 2021; Published 9 June 2021

Academic Editor: François Pérés

Copyright ( 12021 Siaw Frimpong et al. This is an open access article distributed under the Creative Commons Attribution License, which permits unrestricted use, distribution, and reproduction in any medium, provided the original work is properly cited.

\begin{abstract}
This paper employed wavelet coherence and partial wavelet coherence to investigate the time-frequency effect of global economic policy uncertainty on the comovement of five agricultural commodities such as maize, oat, rice, soybean, and wheat using monthly data from January 1997 to December 2019. In general, we observed heterogeneity in comovement structures of the agricultural commodities market at different time-frequency scales which are profound at high frequencies from the bivariate wavelet coherence. The partial wavelet coherence analysis shows that global economic policy uncertainty is a driver of agricultural commodity market connectedness. This implies that extreme changes in economic policy uncertainty have the tendency to influence commodity price comovement. This poses risk to the stability of the agricultural commodities market, which requires the policymaker's intervention to protect against the spillover risk contagion effect in uncertain times.
\end{abstract}

\section{Introduction}

The surge in price and price volatility of agricultural commodities, especially food prices, has attracted the attention of academics, policymakers, investors, farmers, and consumers to this market because of its immediate impact on food security around the world, particularly low-income food-deficit countries. The prices of agricultural commodities have experienced long-term and sharp fluctuations since the year 2000. The prices of major agricultural commodities, from 2006, have generally exhibited upward trends with a sharp fluctuation in 2013 and 2014. These behaviours have attributed to external factors such as macroeconomic uncertainties, agricultural production, financial crises, large and persistent demand, biofuels demand, different stock market phases, and climate warming [1-6]. For example, the outbreak of COVID-19 in 2019 has overturned the stagnation in food prices after its downward trend in 2015-2016. The Food and Agricultural
Organisation Food Price Index surged to its highest level since 2014.

Moreover, the financialization in commodity markets has changed the dependency structure of agricultural commodity markets $[7,8]$. Consequently, the traditional description of commodities in general as an asset class that reliably delivers returns with low correlation to the stock market has changed [9-13]. It instructive to note that agricultural commodity financialization has increased the comovement and volatility spillover within its market and with the traditional asset classes, limiting its diversification benefits [14-17]. The interest of academics and market participants has therefore been drawn to the level of comovement and predictors of commodity prices and volatility spillover $[7,17,18]$. The comovement or otherwise of these commodities provides important information to portfolio investors on diversification opportunities and policymakers on policy interventions to mitigate price fluctuations on the world poorest people. 
Several studies have examined the drivers of agricultural commodities, and different external factors have been identified which include crude oil prices, stock market phases, exchange rate, and production indices [14]. The interdependency structure of agricultural commodity prices has been studied and observed with varying degrees of interdependence [1, 17]. For example, Živkov et al. [7] analysed the comovement structure of five agricultural commodities (corn, wheat, soybean, rice, and oats) using wavelet coherence and phase difference and observed low coherence at shorter time-horizons among the commodities, while periodic coherence at longer time-horizons was found. In the work of Amrouk et al. [17], a multivariate CopulaDCC-GARCH model was employed to investigate the price dynamics among maize, wheat, soybeans, cotton, coffee, cocoa, and sugar futures prices. The results show that the intensity of interaction varies considerably over the sample time but is generally positive and stronger during the period 2007-2012 associated with high commodity prices and financial market stress. A recent study by Yuan [19] showed that agricultural commodity markets of corn, wheat, soybeans, soya oil, cotton, and oats tend to crash (boom) together during extreme events using the Copula-GARCH model.

These strands of findings bring to the fore the fundamental question of what drives commodity price interdependence. The 2007-2011 general boom in international commodity prices has not only been cited as the cause of agricultural commodity hikes but also increases the interdependency [5, 18-20]. Similarly, Wang et al. [6] linked episodes of crisis such as adverse weather, export bans, financial crisis, and depreciation of dollars to the changing behaviour of agricultural commodities (food prices). These have heightened the interest of uncertainty on the behaviour of agricultural commodities.

The theoretical evidence of Keynes [21] and Working [22] identified term structure, hedging pressure, and risk factors as the main drivers of commodity return behaviour. Economic policy uncertainty represents information about the future state of the economy with regards to regulation, fiscal policy, and monetary policy. Pastor and Veronesi [23] theoretical model showed that government economic policy uncertain will lead to both correlations in stock prices and increases in volatilities. By analogy, we expect that global economic policy uncertainty will lead to similar asset price comovements in global financial markets. Frankel [24] showed the importance of monetary policy for commodity prices. As an element of economic policy, Frankel [24] argument on monetary policy also supported the links between economic policy uncertain and commodity prices.

While the above views support the commodity price and economic policy uncertain linkage, one may still ask what about comovement of commodity prices? Policy uncertainty is also found related to corporate investment $[25,26]$. From an investment perspective, global economic policy uncertainty affects investment in the agricultural produces affecting supply and hence the commodity price comovement. Global economic uncertainty also increases calls and attempts for global policy coordination [27]. Such policy coordination in response to global economic policy uncertainty implies that commodity prices may share common shocks. Another channel through which global economic policy uncertain may drive commodity price comovements is the domestic agricultural policy response to global economic policy uncertainty. The intuition is that not all countries are dominant producers of all commodities, and with global economic uncertainty affecting terms of trade, commodity prices comovements will result in the equilibrium as the countries adjust to the global economic policy uncertainty. Based on the number of newspaper articles regarding policy uncertainty from national or regional leading newspapers, Baker et al. $[28,29]$ developed an index to measure EPU, which is more universal and applicable for comparison and can continuously track policy uncertainty.

Subsequently, numerous studies provide ample evidence on the EPU effect on commodity returns (Wang et al. [30]; Reboredo et al. [31]; Shahzad et al. [32]) and economic agents that affect commodity markets such as oil prices and stock returns [33-37]. The role of EPU as the driver of the time variation in asset correlations has also received attention. Fang et al. [38] showed that EPU harms U.S. stock and bond market correlations, while Fang et al. [39] documented a positive policy uncertainty effect on the longrun oil-stock correlation. Recently, Badshah et al. [40] documented that the EPU effect on stock-commodity correlation is stronger during weak economic conditions. As far as we know, there is no previous study that analysis the EPU effect on agricultural commodity price comovement.

This study extends the literature on the EPU effect on asset correlations comovement and examines the effect of EPU on the comovement of agricultural commodities (maize, wheat, soya bean, rice, and oats) returns. The focus on agricultural commodities is motivated by the importance of risk mitigation of food prices to food security concerns. Correlation plays an important role in asset allocation decisions, risk management, and analysis of risk transmission across assets. Specifically, the study provides new evidence by adjusting for the possible influence of EPU using partial wavelet coherence and wavelet coherence, which is lacking in the comovement of agricultural commodities in previous studies (see, for example, Živkov et al. [7]; Amrouk et al. [17]). The advantage of the use of wavelet-based methods is well documented in the literature (see [41-44]). This paper, therefore, investigates the partial correlations in the agricultural commodity prices by including (excluding) the influence of EPU.

\section{Methodology}

The application of wavelet transforms is widespread in time series econometrics to deal with nonstationary problems in time series. Wavelet transforms come in two forms, namely, discrete wavelet transforms (DWT) and continuous wavelet transforms (CWTs). In this paper, we employ only CWT for our analysis since DWT is useful for noise reduction and data compression, while CWT allows for good identification and isolation of periodic signals, by providing a balance between localisation of time and frequency and appears to 
provide a better trade-off between detecting oscillations and peaks or discontinuities [41, 43, 45].

\subsection{Continuous Wavelet Transform and Wavelet Coherence.} The CWT is a powerful technique to assess the dynamics of nonstationary variables over frequency and time domain space. As required, the localized time-frequency space and zero mean must be ensured in the wavelet function decomposition of the time series. This allows for information from the local neighbourhood based on decomposition to be obtained. We specifically employ wavelet coherence under Morlet specification, which is defined as follows:

$$
\Psi_{u, s}(t)=s^{-1 / 2} \Psi\left(\frac{t-u}{s}\right), \Psi(\cdot) \in L^{2}(R),
$$

where $s^{-1 / 2}$ is the normalization factor, which ensures that the unit variance of the wavelet $\Psi_{u, s}(t)^{2}=1 ; u$ is the location parameter, which provides the exact position of the wavelet; and $s$ is the scale dilation parameter, defining how the wavelet is stretched or dilated. Thus, the Morlet wavelet can be defined as follows:

$$
\varphi^{M}(t)=\pi^{-1 / 4} e^{i \omega_{o} t} e^{-t^{2} / 2},
$$

where $\omega_{o}$ is the central frequency of the wavelet. We follow the extant literature to set $\omega_{o}=6[42,45,46]$.

A continuous wavelet transform $W_{x}(u, s)$ is obtained via the projection of a wavelet $\Psi(\cdot)$ on the examined series $x(t)$ so that

$$
W_{x}(u, s)=\int_{-\infty}^{\infty} x(t) s^{-1 / 2} \Psi^{*}\left(\frac{t-u}{s}\right) d t,
$$

where $\Psi^{*}(\cdot)$ is a complex conjugate of $\Psi(\cdot)$. By projecting the specific wavelet $\Psi(\cdot)$ onto the selected time series, we easily obtain $W_{x}(u, s)$. The main advantage of a CWT is its ability to decompose and reconstruct the function $x(t) \in$ $L^{2}(\mathrm{R})$ as follows:

$$
x(t)=\frac{1}{C_{\varphi}} \int_{0}^{\infty}\left[\int_{0}^{\infty} W_{x}(u, s) \Psi_{u, s}(t) d u\right] \frac{d s}{s^{2}}, s>0 .
$$

The power spectrum analysis can then be calculated using Equation (4), with the specification of the variance being

$$
x^{2}=\frac{1}{C_{\varphi}} \int_{0}^{\infty}\left[\int_{0}^{\infty} W_{x}(u, s)^{2} d u\right] \frac{d s}{s^{2}}, s>0
$$

The red noise background spectrum is employed to define the null hypothesis in significance tests for peaks in the wavelet power spectrum. Following Torrence et al. [47] and Torrence et al. [48], the red noise background spectrum is computed using Monte Carlo simulations. Therefore, the corresponding local wavelet power spectrum distribution for each time $n$ and scale $s$ can be

$$
D\left(\frac{W_{n}^{x}(s)^{2}}{\delta_{x}^{2}}<p\right) \Rightarrow \frac{1}{2} P_{f} X_{v}^{2},
$$

where the mean spectrum at Fourier frequency $f$ is denoted by $P_{f}$. The wavelet scale $s$ corresponds to the Fourier frequency $(s 1 / f)$. The real wavelet has $v=1$, and the complex wavelet $v=2$. The variance of the corresponding variable is denoted by $\delta_{x}^{2}$.

Following Rua et al. [44], we define the cross-wavelet transform of two commodities market series $(X)$ and $(Y)$ as follows:

$$
W_{n}^{X Y}(s)=W_{n}^{X}(s) W_{n}^{Y^{*}}(s),
$$

where $W_{n}^{X}(s)$ and $W_{n}^{Y}(s)$ are individual wavelet spectra, $u$ denotes the position, $s$ denotes the scale, and $*$ indicates complex conjugation. The cross-wavelet transform shows the area in time-space with high common power. Therefore, $W_{n}^{Y^{*}}(s)$ is the complex conjugate of $W_{n}^{Y}(s)$. The crosswavelet power $\left|W_{n}^{X Y}(s)\right|$ measures the mutual local covariance on each scale. Therefore, the wavelet coherence of the two time series and $y=\left\{y_{n}\right\}$ is defined by searching the frequency bands and time intervals in which they covary. This provides a useful tool for detecting comovement in commodities markets. Grinsted et al. [38] defined it as the squared absolute value of normalizing a wavelet crossspectrum to a single wavelet power spectrum. Similarly, we define wavelet coherence as squared wavelet coefficient as follows:

$$
R^{2}(x, y)=\frac{\left|S\left(s^{-1} W_{x y}(u, s)\right)\right|^{2}}{S\left(s^{-1}\left|W_{x}(u, s)\right|^{2}\right) S\left(s^{-1}\left|W_{y}(u, s)\right|^{2}\right)},
$$

where $S$ denotes the smoothing parameter, which balances resolution and significance. Also, the bias problem in the wavelet power spectrum and wavelet cross-spectrum is eliminated by the normalizing function of the wavelet coherence. The values of the wavelet coherence coefficient satisfy the inequality $0 \leq R^{2}(x, y) \leq 1$. Wavelet coherence close to one shows a higher similarity between the time series, while coherence near-zero depicts no relationship.

As indicated by Madaleno et al. [49] and Torrence et al. [47], the phase for wavelet depicts any lead/lag linkages between two time series and can be defined as follows:

$$
\varnothing_{x y}=\tan ^{-1}\left(\frac{\mathfrak{I}\left\{W_{n}^{x y}\right\}}{\mathfrak{R}\left\{W_{n}^{x y}\right\}}\right), \varnothing_{x y} \in[-\pi, \pi],
$$

where $\mathfrak{I}$ and $\mathfrak{R}$ are the imaginary and real parts of the smoothed cross-wavelet transform, respectively. In the wavelet coherence map, directional arrows are used to distinguish different phase patterns. For instance, if $x(t)$ and $y(t)$ are in phase (antiphase), the arrow points to the right (left). Similarly, if the arrow points down (or up), this implies that $y(t)$ (or $x(t)$ ) is leading.

2.2. Partial Wavelet Coherence. Wavelet coherence reveals intermittent correlations and provides the significant map when a correlation is real $[43,50,51]$. In the case where there is an intervening effect from a different variable, wavelet coherence is unable to give an accurate correlation. Partial wavelet coherence (PWC) is a technique similar to the partial correlation that helps find the resulting WTC between two time series $x$ and $y$ after eliminating the influence 
of the time series $z$. Similarly, in wavelet applications, PWC can help to eliminate the influence of time series $z(t)$ on the wavelet coherence between $x(t)$ and $y(t)$. Mihanović et al. [52] extended the concept of simple linear correlation and suggested that the PWC can be defined using an equation similar to the partial correlation squared as follows:

$$
R_{p}^{2}(x, y, z)=\frac{\left|R(x, y)-R(x, z) \cdot R(x, y)^{*}\right|^{2}}{[1-R(x, z)]^{2}[1-R(y, z)]^{2}},
$$

where $R_{p}^{2}(x, y, z)$ ranges from 0 to 1 and has a similar interpretation as $R^{2}(x, y)$. Specifically, a low $R_{p}^{2}$ region observed where a high $R^{2}$ region is found indicates that the time series $y$ does not have a significant influence on $x$. Instead, the time series $z$ dominates the variance of $x$. If there is no difference between $R_{p}^{2}$ and $R^{2}$, both $y$ and $z$ have a significant influence on $x$. In this paper, $x$ and $y$ denote the agricultural commodities market returns while $z$ denotes the EPU returns.

2.3. Data and Analysis. The data set for this analysis consists of monthly data on global economic policy uncertainty (EPU) index and monthly period average price of the five major agricultural commodities-maize, wheat, soybean, rice, and oats from January 1997 to December 2019-yielding 276 observations. The period is characterised by considerable global uncertainty, such as the global financial crisis, the sovereign debt crisis in Europe, Brexit, the US presidential election, and US-China trade tension, making it an ideal period for the study. The EPU developed by Baker et al. [28] was obtained from the website https:// www.policyuncertainty.com/index.html and commodity prices from IMF Primary Commodity Prices Database. The analysis was based on the returns of monthly prices/indexes given as

$$
r_{t}=\ln P_{t}-\ln P_{t-1}
$$

where $r_{t}$ is the continuously compounded return and $P_{t}$ and $P_{t-1}$ are the respective current and previous prices/indexes.

We began the analysis by investigating the statistical distribution of returns; it is appropriate to have quick behavioural trajectories of the agricultural commodity prices and returns as well as EPU indices. Figure 1 shows the graphical representation of the trend of the time series plot of both indices and returns of the five agricultural commodities and EPU over the study period. A glance shows that all the commodity indices were trending upward and exhibited quite a similarity in dynamic patterns until the outbreak of the global financial crisis and then plunged in 2008. Recovery was observed between 2010 and 2013 and then nosedived until 2018. The recovery from 2018 has been one of a mixed.

The EPU, however, generally showed an upward trend over the study period except between 2003 and 2007. This is expected because of episodes of global financial and political uncertainty in recent years. This trajectory behaviour of all indices might induce correlations among them. Table 1 presents the pairwise correlation among the indices, and the results showed low to moderate correlation among the agricultural commodities and no correlation with EPU.

A glance at the descriptive statistics of the return presented in Table 2 reveals key features of the return rates of the series included in the study. All the return series had positive means in the period considered, and only two out of the six series had negative skewness. The negatively skewed returns indicate that higher losses are more frequent than higher gains. The returns of all series are relatively symmetrical except for rice. All the series depart from normality with high kurtosis except for oats, which means that the returns are heavy-tailed relative to a normal distribution. This is not surprising as it is a well-known stylized fact of assets in the financial literature [53].

In the first step, the pairwise wavelet coherence plots of the five selected agricultural commodities are presented as a benchmark before investigating the partial wavelet coherence. The wavelet coherence maps are used in this study to assess the strength of the interdependence both in time and frequency domains. The time component is displayed on the horizontal axis, while the vertical axis displays the frequency (the lower the frequency, the higher the scale). The region in time-frequency space where the pair-wise time series covary is indicated by the warm colour. The strength of the interdependence between paired series is indicated by the colour of the surface and depicted by the colour pallet. The warmer colour (red) represents regions with significant interrelation, while the colder colour (blue) signifies a lower dependence between the series. The crosshatch indicates regions inside the cone of influence, and the thick black contour indicates a 95\% confidence level obtained from the Monte Carlo simulations, whereby cold regions beyond the significant areas represent time and frequency with no dependence in the series. An arrow in the wavelet coherence plot shows the lead/lag phase relations between the paired series. A zero-phase difference means that the two paired time series move together on a particular scale. When the arrows point to the right, the paired time series are said to be in phase (move in the same direction), while the arrows to the left indicate antiphase (move in the opposite direction). Arrows pointing to the right-down or left-up indicate that the first variable is leading, while arrows pointing to the right-up or left-down show that the second variable is leading.

Figure 2 shows the partial and bivariate wavelet coherence explaining the pairwise coherence plots between maize, wheat, soybean, rice, and oats with EPU as a covariate variable. The results of bivariate wavelet coherence are presented on the left-hand side, whereas that of partial wavelet coherence on the right-hand side. The wavelet coherence map in Figure 2(a) shows that the comovement between oats and the rest of the agricultural commodities such as maize, wheat, soybean, and rice is primarily concentrated in 0-32 month cycles. Several small islands were observed in a period of 0-8 month cycles throughout the study period and extended to 32 month cycles with intense connectedness between 2007 and 2013. Maize, however, showed strong interdependence with rice, soya bean, and wheat. It is worthy to note that maize perfectly serves as both 

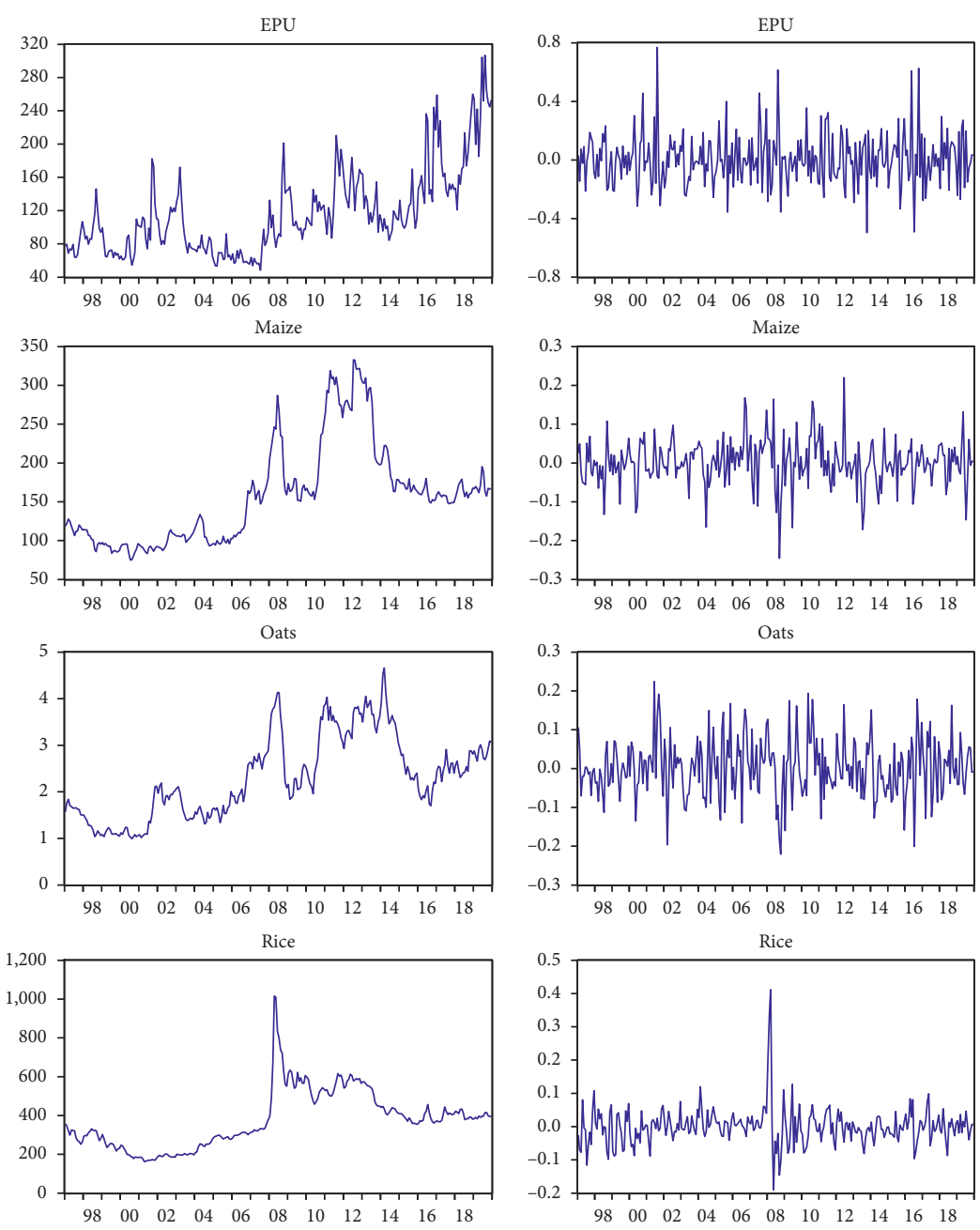

Soya bean
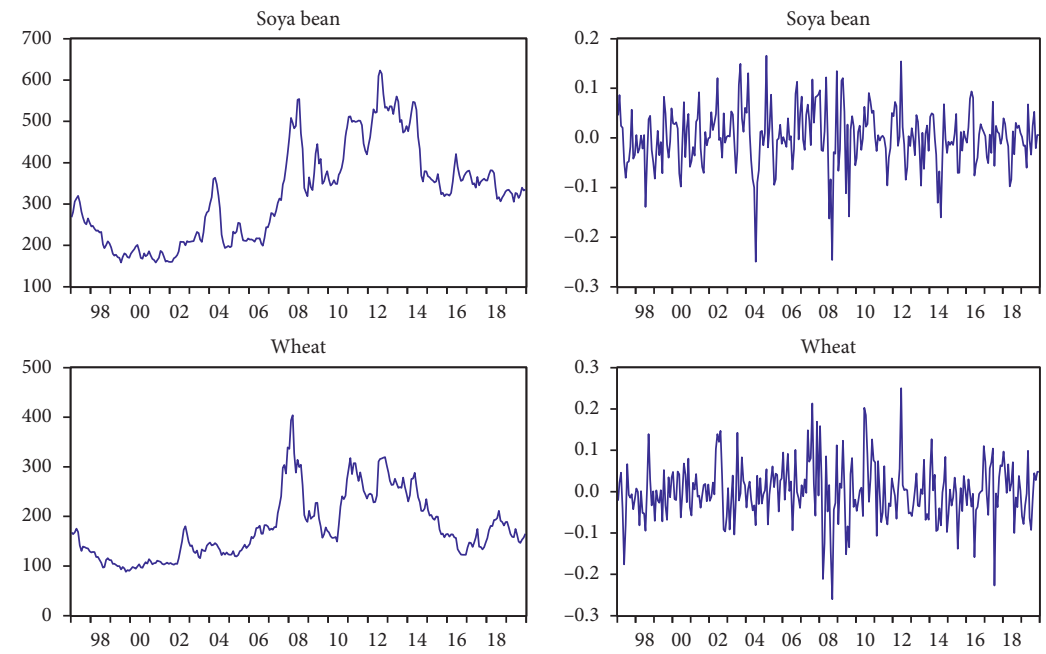

Figure 1: The plot of the raw series (left) and returns series (right).

a substitute and complements to these classes of cereals and therefore not a surprise to have its price returns highly connected. The coherence is very strong at $64-128$ month cycle for all periods of study and gradually for all months' cycle after 2018. The comovements between rice, soya bean, and wheat are not different from the interrelations of maize with rice, soybean, and wheat. In general, the pattern of pairewise comovements among the agricultural commodities is in phase, but it is not clear which leads the market. It is important to note that in all cases, the correlations were profound during the period characterising the commodity price boom and the global financial crisis. This observation is consistent with the findings of prior studies that the price returns of related agricultural commodities move together 
TABLE 1: Correlation matrix of EPU and selected agricultural commodities.

\begin{tabular}{|c|c|c|c|c|c|c|}
\hline & EPU & Maize & Oats & Rice & Soya bean & Wheat \\
\hline EPU & 1.0000 & & & & & \\
\hline Maize & 0.0089 & 1.0000 & & & & \\
\hline Oats & -0.0005 & $0.4965^{* * *}$ & 1.0000 & & & \\
\hline Rice & -0.0086 & $0.1077^{*}$ & $0.1098^{*}$ & 1.0000 & & \\
\hline Soya beans & -0.0755 & $0.6555^{* * *}$ & $0.3685^{* * *}$ & 0.0446 & 1.0000 & \\
\hline Wheat & -0.0076 & $0.5588^{* * *}$ & $0.3572^{* * *}$ & -0.0663 & $0.4931^{* * *}$ & 1.0000 \\
\hline
\end{tabular}

${ }^{*},{ }^{* *}$, and ${ }^{* * *}$ represent $10 \%, 5 \%$, and $1 \%$ significance levels, respectively.

Table 2: Descriptive statistics.

\begin{tabular}{|c|c|c|c|c|c|c|}
\hline & EPU & Maize & Oat & Rice & Soya & Wheat \\
\hline Mean & 0.0044 & 0.0013 & 0.0024 & 0.0004 & 0.0008 & 0.0001 \\
\hline Median & -0.0061 & 0.0010 & 0.0026 & -0.0027 & 0.0019 & -0.0009 \\
\hline Maximum & 0.7690 & 0.2197 & 0.2242 & 0.4116 & 0.1656 & 0.2502 \\
\hline Minimum & -0.4964 & -0.2455 & -0.2205 & -0.1901 & -0.2495 & -0.2602 \\
\hline Std. dev. & 0.1770 & 0.0583 & 0.0745 & 0.0553 & 0.0589 & 0.0695 \\
\hline Skewness & 0.6474 & -0.2158 & 0.1281 & 2.1990 & -0.4524 & 0.0787 \\
\hline Kurtosis & 4.9170 & 5.1900 & 3.4231 & 18.4220 & 5.0797 & 4.6689 \\
\hline Jarque-Bera & $61.5388^{* * *}$ & $57.3005^{* * *}$ & 2.8136 & $2957.5670^{* * *}$ & $59.1504^{* * *}$ & $32.3154^{* * *}$ \\
\hline Observations & 275 & 275 & 275 & 275 & 275 & 275 \\
\hline
\end{tabular}

${ }^{*},{ }^{* *}$, and ${ }^{* * *}$ indicate $10 \%, 5 \%$, and $1 \%$ significance level, respectively.
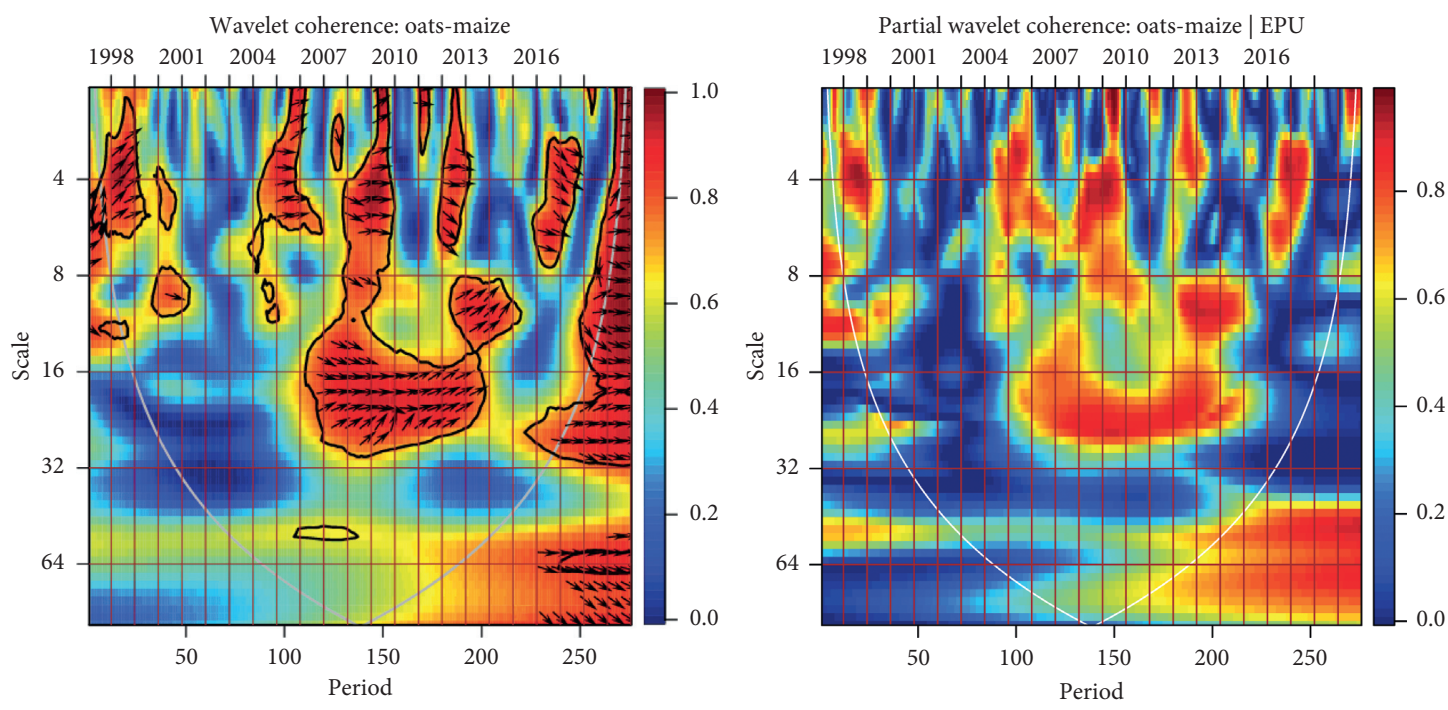

Wavelet coherence: oats-rice

$\begin{array}{lllllll}1998 & 2001 & 2004 & 2007 & 2010 & 2013 & 2016\end{array}$

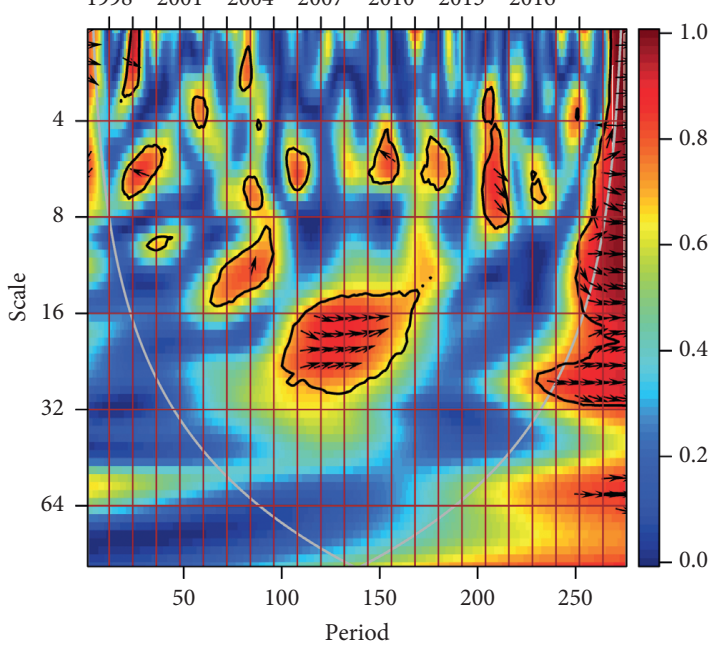

Partial wavelet coherence: oats-rice | EPU

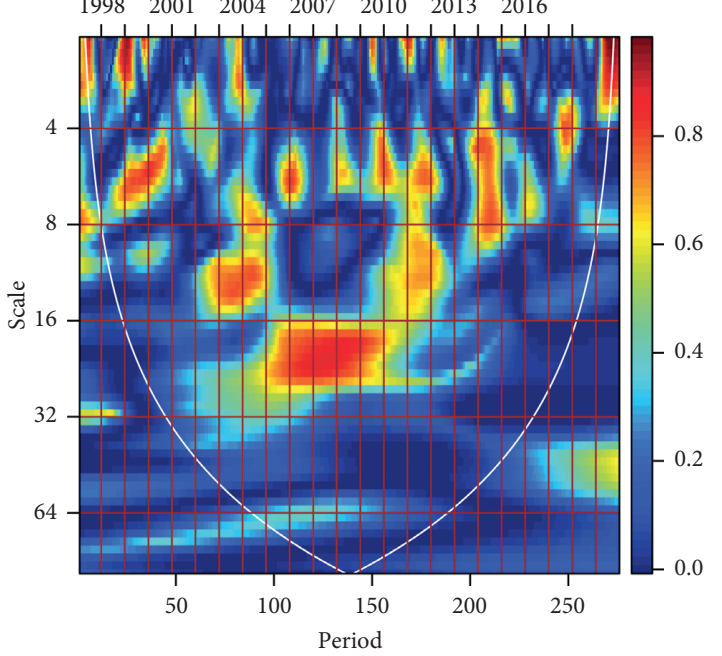

(a)

Figure 2: Continued. 

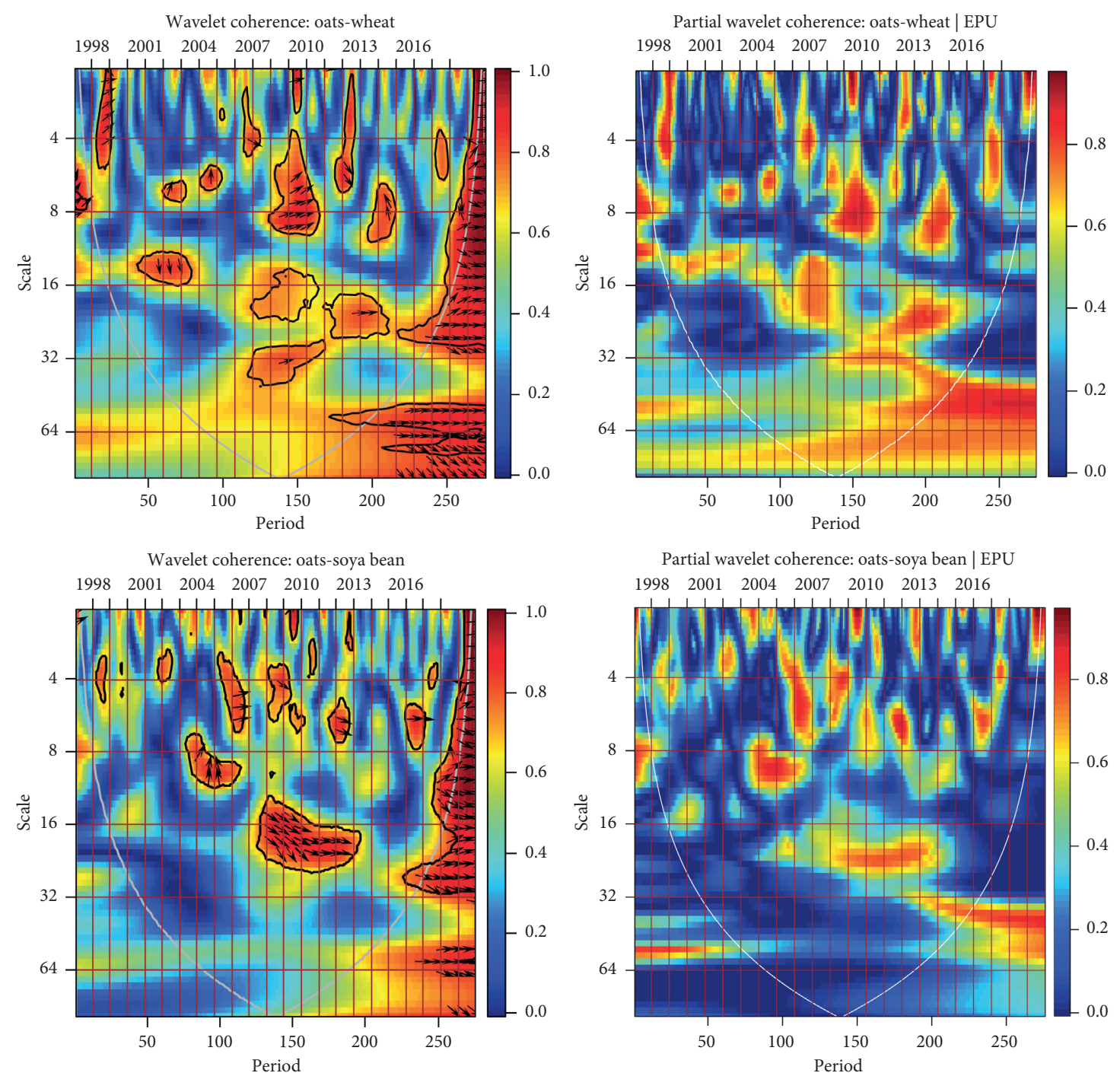

(b)

Figure 2: Continued. 
Wavelet coherence: maize-rice

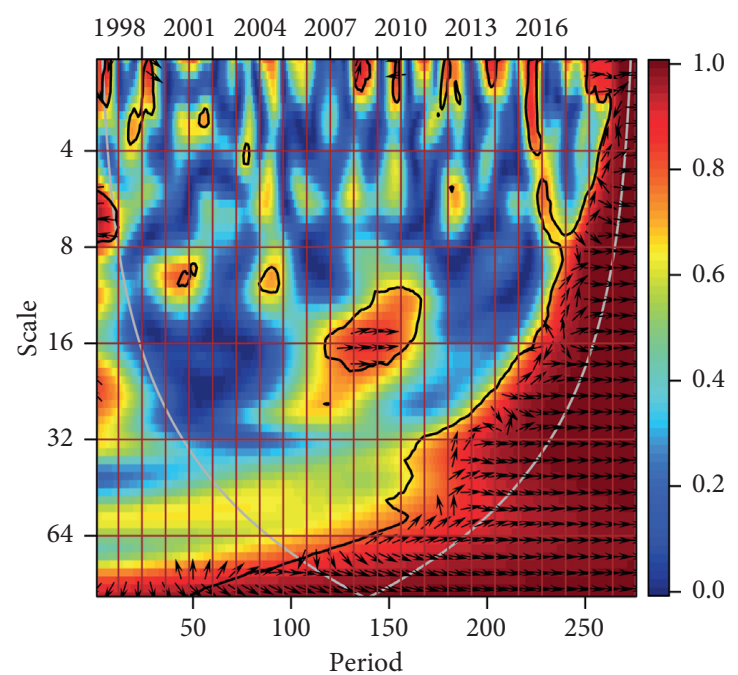

Wavelet coherence: maize-wheat

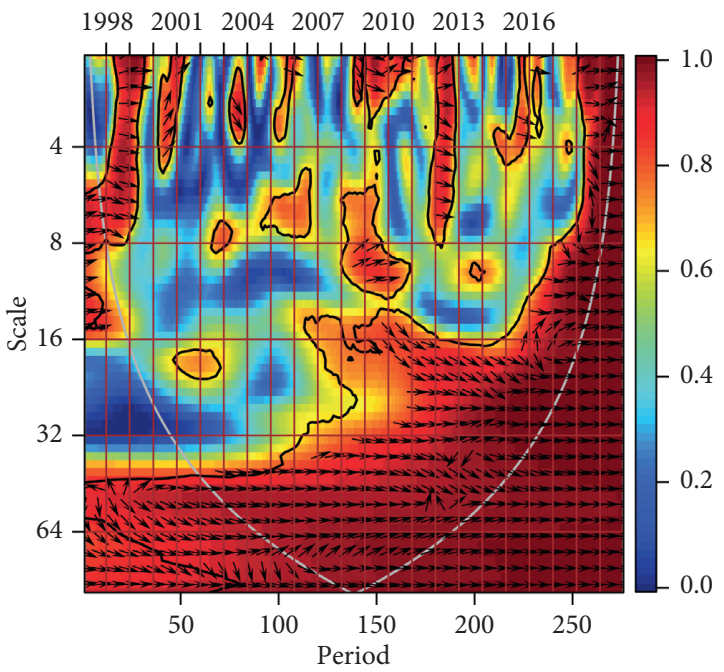

Partial wavelet coherence: maize-rice |EPU

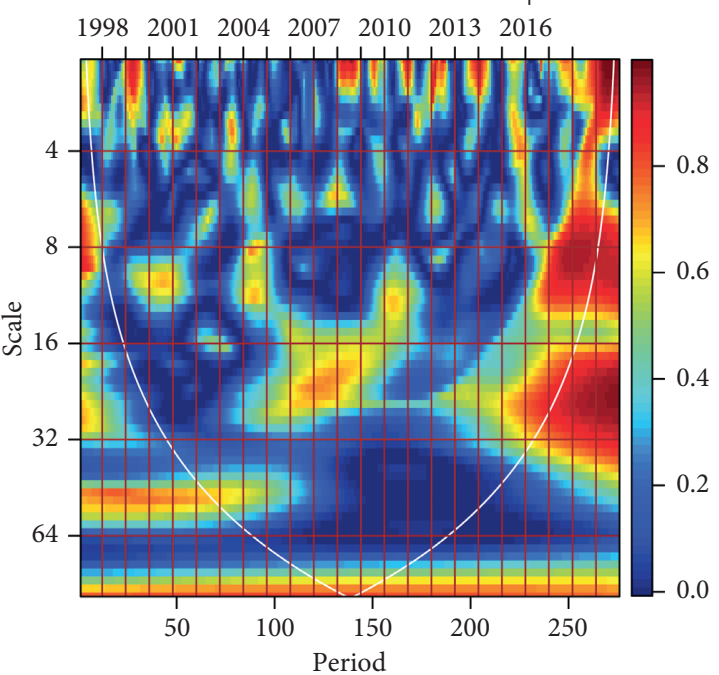

Partial wavelet coherence: maize-wheat | EPU 1998200120042007201020132016

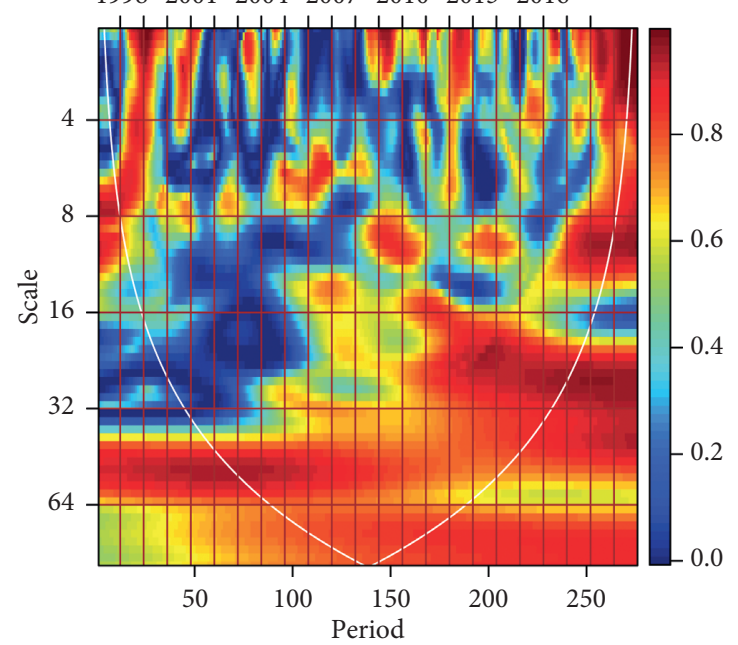

(c)

FIgUre 2: Continued. 

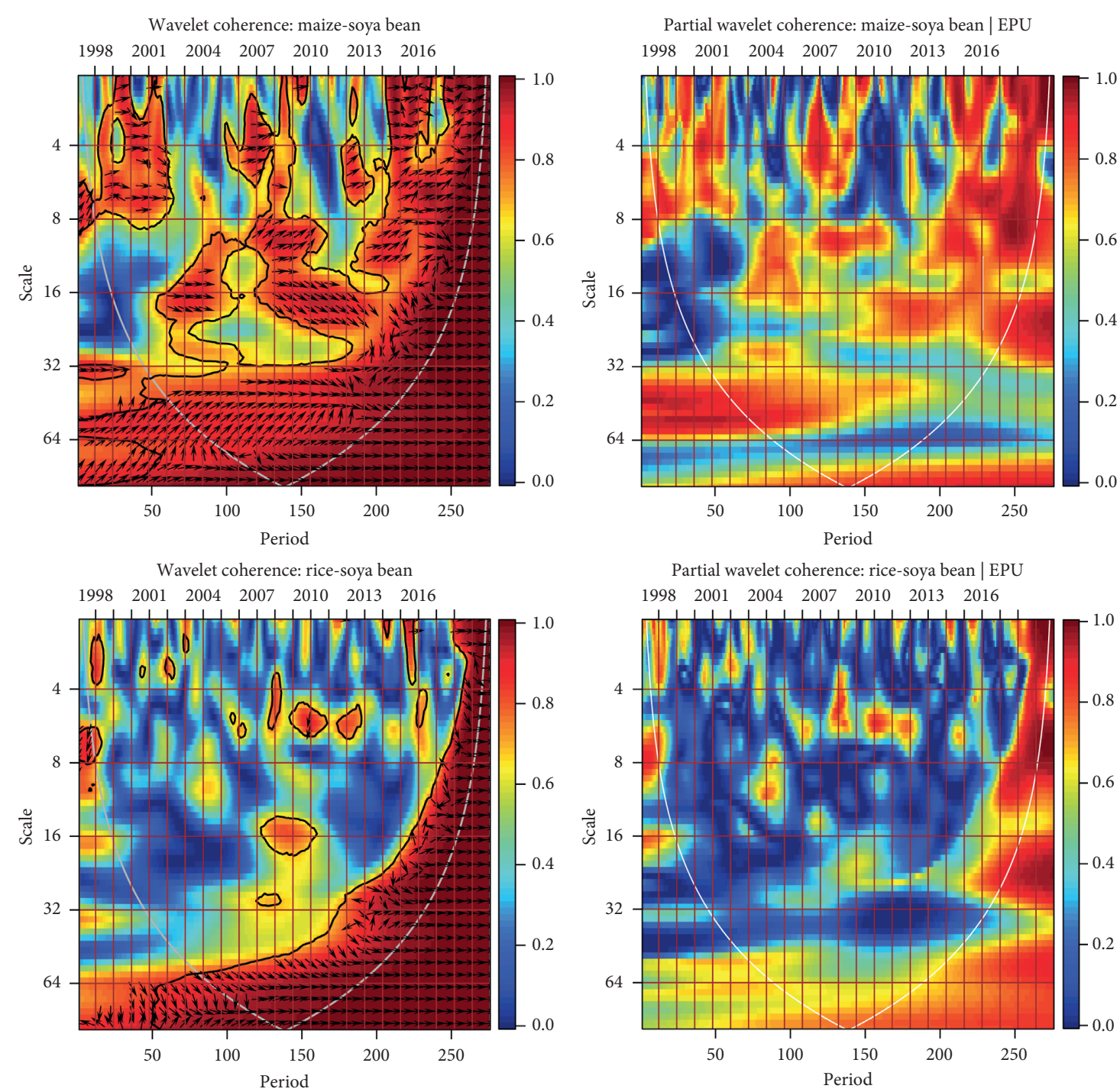

(d)

FIGURE 2: Continued. 

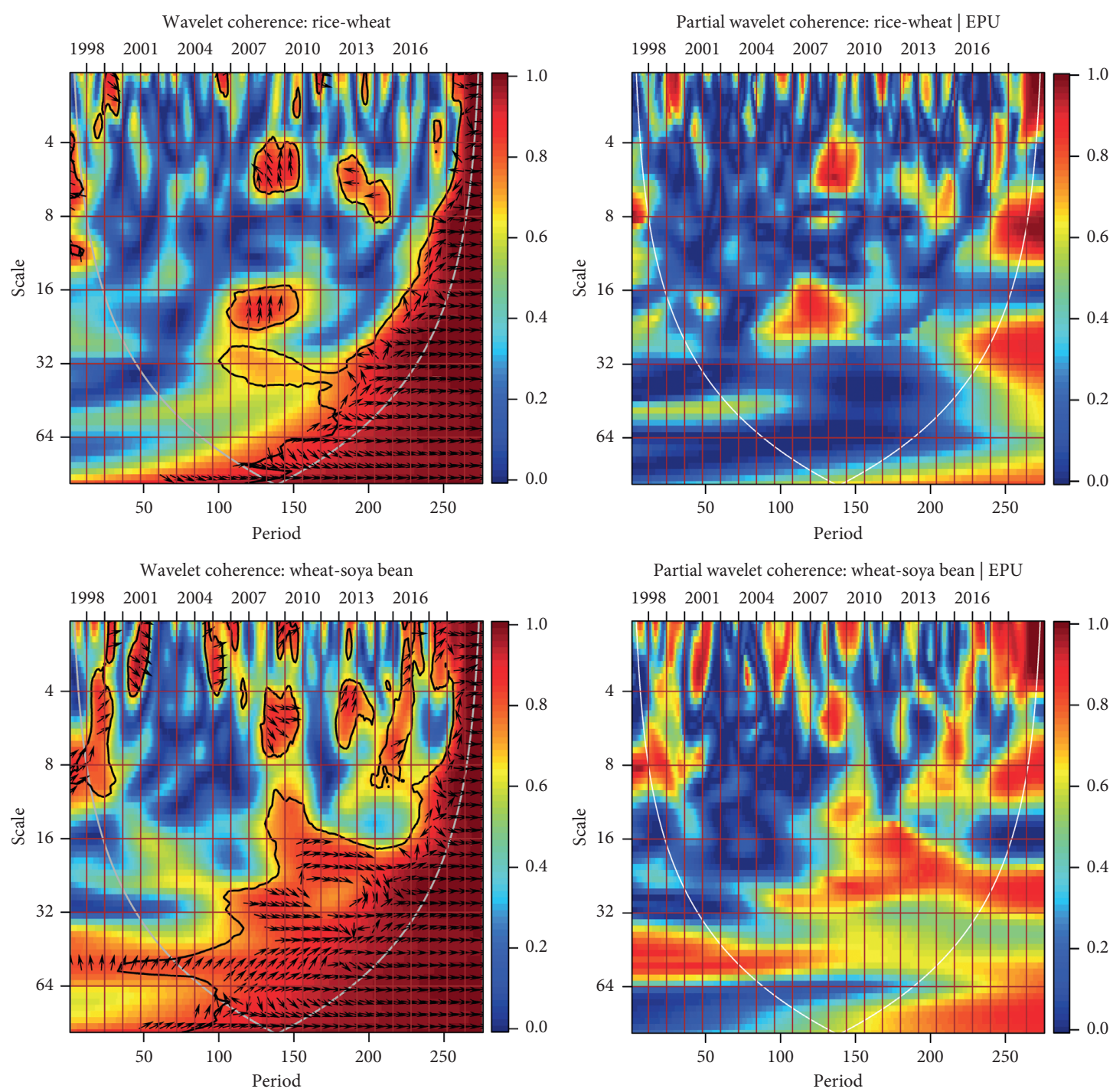

(e)

FIGURE 2: The left side plots bivariate wavelet coherence between commodity markets. The right side illustrates the plots of partial wavelet coherence between commodities markets when the effect of global economic policy is removed.

$[19,54]$. In particular, we detected a high correlation during the financial crisis between the five agricultural commodities (corn, wheat, soybean, rice, and oats) similar to Živkov et al. [7] and Yuan [19] but more profound coherence. The difference in comovement structure emanates from the frequency of the data used; daily data are susceptible to speculation and noisy behaviour. The right side of Figure 2 illustrates the partial wavelet coherence among the commodities prices such as maize, wheat, soybean, rice, and oats with EPU as a covariate variable (i.e., excluding the influence of EPU). A substantial decrease in the strength of the coherence area among the commodities in all cases for the partial wavelet coherence indicates that EPU is a key driver of the comovement of the selected commodity prices. The finding highlights the importance of economic policy uncertainty as a driver of assets prices connectedness across financial markets, particularly commodity prices following the financialization of commodity markets [17, 55-57]. The financialization of commodity markets has affected the information transfer, improves market liquidity, and strengthens the commodity equity market comovement, making commodity prices susceptible to drivers of financial markets $[4,15,17,19,20,58,59]$. In summary, uncertainty in global economic policy as a significant driver of comovement between agricultural commodities price returns has policy implications. It suggests a greater integration of agricultural commodity markets with prices booming and crashing together during uncertain times. This calls for policymakers to devise strategies to mitigate economic policy uncertainty shocks to agricultural commodity prices. Again, the interdependency in the market poses risk to the stability of the agricultural commodities market, which requires the policymaker's intervention to protect against the spillover risk contagion effect in uncertain times. The correlation of assets is key in portfolio construction, diversification, and risk management in asset markets. The 
differences in correlation structure at different time scales present unique information on both contagion and interdependence which are critical for commodity traders who desired to form a portfolio of agricultural commodities. The wavelet coherence at high frequency signifies contagion and interdependence at low frequencies. Consequently, investors must employ different trading strategies for different investment horizons. For example, oats correlate less with all other commodities in high time scales, and therefore the inclusion of oats in commodities portfolio will require a longer investment horizon to minimise the variance of the portfolio. By applying partial wavelet coherence using global economic policy uncertainty as a covariate, new information is provided to investors. A sharp decline of the comovement in any paired commodities suggests that economic policy uncertainties limit the diversification benefits of the agricultural commodities portfolio. It is therefore important that investors pay attention to global risk factors which tend to create uncertainty in economic policies. The comovement of agricultural commodities, especially upward movement, poses a threat to food insecurity to the poorest population. The evidence of sizable price spikes in times of uncertainty requires the government to implement policy interventions to minimise its impact on the poorest populations which will be enhanced through policy intervention.

\section{Conclusion}

This paper investigates the time-frequency effect of economic policy uncertainty on the comovement of five agricultural commodities using wavelet coherence and partial wavelet coherence. A monthly average price of maize, oat, rice, soybeans, and wheat from January 1997 to December 2019 as well as global economic policy uncertainty of the same frequency for the same period was used. The use of bivariate wavelet coherence together with partial wavelet coherence overcomes the problems of variation in timefrequency space and traditional two-variable methods of calculating comovement. The use of economic policy uncertainty as a covariate for the comovement between agricultural commodity returns provides a better understanding and information on the interaction of agricultural commodities markets.

The result from bivariate wavelet coherence shows heterogeneity in the comovement structure of the agricultural commodities market at different time-frequency scales which are profound at high frequencies. It is also evident that maize correlates strongly with all agricultural commodities studied. Similar to partial correlation, partial wavelet coherence analysis provides the resulting wavelet coherence between agricultural commodity prices after eliminating common factors of dependency of global economic policy uncertainty. By removing the effect of global economic policy uncertainty, a substantial decrease in the strength of the coherence area among the commodities in all cases was observed. Thus, according to the partial wavelet coherence analysis, global economic policy uncertainty drives the comovement of commodity prices.
The heterogeneity of correlation structure at different time scales presents unique information to commodity traders desired to form a portfolio of agricultural commodities for trading strategies to adopt. A sharp decline in the comovement of any paired commodities suggests that economic policy uncertainties limit the diversification benefits of the agricultural commodities portfolio. It is therefore important that investors pay attention to global risk factors, which tends to create uncertainty in economic policies. The comovement of agricultural commodities, especially upward movement, poses a threat to food insecurity to the poorest population. The evidence of sizable price spikes in times of uncertainty requires the government to implement policy interventions to minimise its impact on the poorest populations which will be enhanced through policy intervention.

\section{Data Availability}

The data used in this paper were collected from the IMF Primary Commodity Price System (website: https://data.imf. org/?sk=471DDDF8-D8A7-499A-81BA-5B332C01F8B9).

Since this study used secondary data from the official source of IMF, the authors, therefore, decided not to reshare.

\section{Disclosure}

This study was carried out as a part of employment as lectures at the University of Cape Coast and Ghana Institute of Management and Public Administration.

\section{Conflicts of Interest}

The authors declare that they have no conflicts of interest.

\section{References}

[1] B. J. Henderson, N. D. Pearson, and L. Wang, "New evidence on the financialization of commodity markets," The Review of Financial Studies, vol. 28, no. 5, pp. 1287-1311, 2015.

[2] K. J. Singleton, "Investor flows and the 2008 boom/bust in oil prices," Management Science, vol. 60, no. 2, pp. 300-318, 2014.

[3] T. Wheeler and J. Von Braun, "Climate change impacts on global food security," Science, vol. 341, no. 6145, pp. 508-513, 2013.

[4] G. Tadesse, B. Algieri, M. Kalkuhl, and J. von Braun, "Drivers and triggers of international food price spikes and volatility," Food Policy, vol. 47, pp. 117-128, 2014.

[5] J. D. Hamilton and J. C. Wu, "Effects of index-fund investing on commodity futures prices," International Economic Review, vol. 56, no. 1, pp. 187-205, 2015.

[6] L. Wang, W. Duan, D. Qu, and S. Wang, "What matters for global food price volatility?" Empirical Economics, vol. 54, no. 4, pp. 1549-1572, 2017.

[7] D. Živkov, J. Njegić, and M. Pećanac, "Multiscale interdependence between the major agricultural commodities," Agricultural Economics Czech, vol. 65, pp. 82-92, 2019.

[8] M. A. Hernandez, R. Ibarra, and D. R. Trupkin, "How far do shocks move across borders? Examining volatility transmission in major agricultural futures markets," European Review of Agricultural Economics, vol. 41, no. 2, pp. 301-325, 2014. 
[9] H. Bessembinder, "Systematic risk, hedging pressure, and risk premiums in futures markets," Review of Financial Studies, vol. 5, no. 4, pp. 637-667, 1992.

[10] H. Bessembinder and K. Chan, "Time-varying risk premia and forecastable returns in futures markets," Journal of Financial Economics, vol. 32, no. 2, pp. 169-193, 1992.

[11] G. Gorton and K. G. Rouwenhorst, "Facts and fantasies about commodity futures," Financial Analysts Journal, vol. 62, no. 2, pp. 47-68, 2006.

[12] K. Tang and W. Xiong, "Index investment and the financialization of commodities," Financial Analysts Journal, vol. 68, no. 6, pp. 54-74, 2012.

[13] Z. Adams and T. Glück, "Financialization in commodity markets: a passing trend or the new normal?" Journal of Banking \& Finance, vol. 60, pp. 93-111, 2015.

[14] D. Matošková, "Volatility of agrarian markets aimed at the price development," Agricultural Economics - Czech, vol. 57, pp. 34-40, 2011.

[15] S. H. Irwin and D. R. Sanders, "Financialization and structural change in commodity futures markets," Journal of Agricultural and Applied Economics, vol. 44, no. 3, pp. 371-396, 2012.

[16] L. Baldi, M. Peri, and D. Vandone, "Stock markets' bubbles burst and volatility spillovers in agricultural commodity markets," Research in International Business and Finance, vol. 38, pp. 277-285, 2016.

[17] E. M. Amrouk, S.-C. Grosche, and T. Heckelei, "Interdependence between cash crop and staple food international prices across periods of varying financial market stress," Applied Economics, vol. 52, no. 4, pp. 345-360, 2020.

[18] C. Wei Su, X.-Q. Wang, R. Tao, and L. Oana-Ramona, "Do oil prices drive agricultural commodity prices? Further evidence in a global bio-energy context," Energy, vol. 172, pp. 691-701, 2019.

[19] X. Yuan, J. Tang, W.-K. Wong, and S. Sriboonchitta, "Modeling Co-movement among different agricultural commodity markets: a copula-GARCH approach," Sustainability, vol. 12, no. 1, p. 393, 2020.

[20] D. Headey and S. Fan, "Anatomy of a crisis: the causes and consequences of surging food prices," Agricultural Economics, vol. 39, pp. 375-391, 2008.

[21] J. M. Keynes, A Treatise on Money, Macmillan, New York, NY, USA, 1930.

[22] H. Working, "The theory of the price of storage," American Economic Review, vol. 39, pp. 1254-1262, 1949.

[23] L. Pástor and P. Veronesi, "Uncertainty about government policy and stock prices," The Journal of Finance, vol. 67, no. 4, pp. 1219-1264, 2012.

[24] J. A. Frankel, "The effect of monetary policy on real commodity prices," in Asset Prices and Monetary Policy, J. Campbell, Ed., pp. 291-333, 2008.

[25] H. Gulen and M. Ion, "Policy uncertainty and corporate investment," The Review of Financial Studies, vol. 29, no. 3, pp. 523-564, 2016.

[26] D. Rodrik, "Policy uncertainty and private investment," Journal of Development Economics, vol. 36, no. 2, pp. 229-242, 1991.

[27] J. A. Frankel, International Coordination (No. W21878), National Bureau of Economic Research, Cambridge, Massachusetts, USA, 2016.

[28] S. R. Baker, N. Bloom, and S. J. Davis, "Measuring economic policy uncertainty*," The Quarterly Journal of Economics, vol. 131, no. 4, pp. 1593-1636, 2016.
[29] S. R. Baker, N. Bloom, and S. J. Davis, "Measuring economic policy uncertainty," National Bureau of Economic Research, vol. 131, 2015.

[30] Y. Wang, B. Zhang, X. Diao, and C. Wu, "Commodity price changes and the predictability of economic policy uncertainty," Economics Letters, vol. 127, pp. 39-42, 2015.

[31] J. C. Reboredo and X. Wen, "Are China's new energy stock prices driven by new energy policies?” Renewable and Sustainable Energy Reviews, vol. 45, pp. 624-636, 2015.

[32] S. J. H. Shahzad, N. Raza, M. Balcilar, S. Ali, and M. Shahbaz, "Can economic policy uncertainty and investors sentiment predict commodities returns and volatility?" Resources Policy, vol. 53, pp. 208-218, 2017.

[33] T. P. Wisniewski and B. J. Lambe, "Does economic policy uncertainty drive CDS spreads?" International Review of Financial Analysis, vol. 42, pp. 447-458, 2015.

[34] M. Arouri, C. Estay, C. Rault, and D. Roubaud, "Economic policy uncertainty and stock markets: long-run evidence from the US," Finance Research Letters, vol. 18, pp. 136-141, 2016.

[35] Z. Liu, Y. Ye, F. Ma, and J. Liu, "Can economic policy uncertainty help to forecast the volatility: a multifractal perspective," Physica A: Statistical Mechanics and Its Applications, vol. 482, pp. 181-188, 2017.

[36] C. T. Albulescu, R. Demirer, I. D. Raheem, and A. K. Tiwari, "Does the U.S. economic policy uncertainty connect financial markets? Evidence from oil and commodity currencies," Energy Economics, vol. 83, pp. 375-388, 2019.

[37] A. M. Adam, "Susceptibility of stock market returns to international economic policy: evidence from effective transfer entropy of Africa with the implication for open innovation," Journal of Open Innovation: Technology, Market, and Complexity, vol. 6, no. 3, p. 71, 2020.

[38] L. Fang, H. Yu, and L. Li, "The effect of economic policy uncertainty on the long-term correlation between U.S. stock and bond markets," Economic Modelling, vol. 66, pp. 139-145, 2017.

[39] H. Yu, L. Fang, B. Sun, and D. Du, "Risk contribution of the Chinese stock market to developed markets in the post-crisis period," Emerging Markets Review, vol. 34, pp. 87-97, 2018.

[40] I. Badshah, R. Demirer, and M. T. Suleman, "The effect of economic policy uncertainty on stock-commodity correlations and its implications on optimal hedging," Energy Economics, vol. 84, Article ID 104553, 2019.

[41] P. Owusu Junior, A. M. Adam, and G. Tweneboah, "Comovement of real exchange rates in the west african monetary zone," Cogent Economics \& Finance, vol. 5, no. 1, Article ID 1351807, 2017.

[42] P. Owusu junior, G. Tweneboah, and A. M. Adam, "Interdependence of major exchange rates in Ghana: a wavelet coherence analysis," Journal of African Business, vol. 20, no. 3 , 2019.

[43] K. Wu, J. Zhu, M. Xu, and L. Yang, "Can crude oil drive the co-movement in the international stock market? Evidence from partial wavelet coherence analysis," The North American Journal of Economics and Finance, vol. 53, Article ID 101194, 2020.

[44] E. Asafo-Adjei, D. Agyapong, S. K. Agyei, S. Frimpong, R. Djimatey, and A. M. Adam, "Economic policy uncertainty and stock returns of Africa: a wavelet coherence analysis," Discrete Dynamics in Nature and Society, vol. 2020, Article ID 8846507, 8 pages, 2020.

[45] A. Grinsted, J. C. Moore, and S. Jevrejeva, "Application of the cross wavelet transform and wavelet coherence to geophysical 
time series," Nonlinear Processes in Geophysics, vol. 11, no. 6, pp. 561-566, 2004.

[46] A. Rua and L. C. Nunes, "International comovement of stock market returns: a wavelet analysis," Journal of Empirical Finance, vol. 16, no. 4, pp. 632-639, 2009.

[47] C. Torrence and G. P. Compo, "A practical guide to wavelet analysis," Bulletin of the American Meteorological Society, vol. 79, no. 1, pp. 61-78, 1998.

[48] C. Torrence and P. J. Webster, "Interdecadal changes in the ENSO-monsoon system," Journal of Climate, vol. 12, no. 8, pp. 2679-2690, 1999.

[49] M. Madaleno and C. Pinho, "International stock market indices comovements: a new look," International Journal of Finance \& Economics, vol. 17, no. 1, pp. 89-102, 2012.

[50] K. Gurley and A. Kareem, "Discussion," Engineering Structures, vol. 21, no. 2, pp. 149-167, 1999.

[51] K. Gurley, T. Kijewski, and A. Kareem, "First- and higherorder correlation detection using wavelet transforms," Journal of Engineering Mechanics, vol. 129, no. 2, pp. 188-201, 2003.

[52] H. Mihanović, M. Orlić, and Z. Pasrić, "Diurnal thermocline oscillations driven by tidal flow around an island in the Middle Adriatic," Journal of Marine Systems, vol. 78, pp. 157-168, 2009.

[53] E. Pereira, P. JS. Ferreira, M. F. da Silva, J. GV. Miranda, and H. BB. Pereira, "Multiscale network for 20 stock markets using DCCA," Journal of Physics A, vol. 529, Article ID 121542, 2019.

[54] F. D. Nicola, P. De Pace, and M. A. Hernandez, "Comovement of major energy, agricultural, and food commodity price returns: a time-series assessment," Energy Economics, vol. 57, pp. 28-41, 2016.

[55] E. Nier, T. S. Sedik, and T. Mondino, "Gross private capital flows to emerging markets: can the global financial cycle be tamed?" IMF Working Papers International Monetary Fund, vol. 48, pp. 14-196, 2014.

[56] E. Passari and H. Rey, "Financial flows and the international monetary system," The Economic Journal, vol. 125, no. 584, pp. 675-698, 2015.

[57] H. Rey, "International channels of transmission of monetary policy and the mundellian trilemma," IMF Economic Review, vol. 64, no. 1, pp. 6-35, 2016.

[58] S. H. Irwin, "Commodity index investment and food prices: does the masters hypothesis explain recent price spikes?" Agricultural Economics, vol. 44, pp. 29-41, 2013.

[59] I. Goldstein and L. Yang, "Commodity financialization and information transmission," Working Paper, 2018. 